\title{
Beatriz Ercolin
}

Caracterização da deglutição em portadores de distrofia miotônica de Steinert

Dissertação apresentada à Faculdade de Medicina da Universidade de São Paulo para obtenção do título de Mestre em Ciências

Programa de: Ciências da Reabilitação Área de Concentração: Comunicação Humana

Orientadora: Dra. Fernanda Chiarion Sassi

\section{SÃO PAULO}


Dados Internacionais de Catalogação na Publicação (CIP)

Preparada pela Biblioteca da

Faculdade de Medicina da Universidade de São Paulo

Creprodução autorizada pelo autor

Ercolin, Beatriz

Caracterização da deglutição em portadores de distrofia miotônica de Steinert

/ Beatriz Ercolin. -- São Paulo, 2012.

Dissertação(mestrado)--Faculdade de Medicina da Universidade de São Paulo. Programa de Ciências da Reabilitação. Área de concentração: Comunicação Humana.

Orientadora: Fernanda Chiarion Sassi.

Descritores: 1.Disfagia 2.Distrofia miotônica 3.Eletromiografia de superfície 4.Deglutição 5.Transtornos de deglutição

USP/FM/DBD-344/12 
DEDICATÓRIA

Dedico este trabalho a todos os portadores de Distrofia Miotônica, expressando o meu desejo de melhor qualidade de vida a esses pacientes. 


\section{AGRADECIMENTOS}

Agradeço a Deus e ao meu Anjo da Guarda, pela permissão concedida e por me guiarem durante todo o percurso para a realização e término deste trabalho.

Aos meus pais, Roberto e Magali pelo amor incondicional e por me incentivarem ao estudo.

Aos meus irmãos Rafael e Renato pelo apoio e pelos momentos de descontração.

Ao meu marido Tiago, o grande amor da minha vida, pelo incentivo ’as minhas realizações profissionais.

À querida Dra Fernanda Sassi, pelo imenso aprendizado, pela confiança depositada, carinho e atenção que me foi dispensada.

Aos pacientes deste estudo e seus familiares, que são o maior sentido da realização deste trabalho.

Às médicas neurologistas Dra Suely Kazue Nagahashi Marie e Dra Mary Souza de Carvalho pelos ensinamentos e viabilização deste estudo. 
Aos funcionários do ambulatório de Miopatias do Hospital das Clínicas da Faculdade de Medicina da Universidade de São Paulo, pela ajuda, simpatia e agradável convívio durante esta etapa.

À Profa. Dra Claudia Regina Furquim de Andrade, pela exemplar conduta e seriedade na construção da ciência da Fonoaudiologia, pelos seus ensinamentos e conquistas no Hospital das Clínicas da Faculdade de Medicina da Universidade de São Paulo.

‘As fonoaudiólogas e lindas amigas, Laura Davison Mangilli, Fabiola S. Juste, Gisele C. de Medeiros e Danielle P. Moraes, pela cumplicidade, auxilio e carinho.

Ao Aristide Correia, pela disponibilidade e atenção com a analise estatística do estudo.

À Dra Lucia Iracema Zanotto de Mendonça, à Profa. Suely Cecília Olivan Limongi e à Profa. Dra Claudia Regina Furquim de Andrade, pela participação na minha banca de qualificação, que contribuíram brilhantemente para melhor compreensão da amplitude deste estudo. 
'Aprenda como se você fosse viver para sempre.

Viva como se você fosse morrer amanhã' 
NORMALIZAÇÃO ADOTADA

Esta dissertação ou tese está de acordo com as seguintes normas, em vigor no momento desta publicação:

Referências: adaptado de International Committee of Medical Journals Editors (Vancouver).

Universidade de São Paulo. Faculdade de Medicina. Divisão de Biblioteca e Documentação. Guia de apresentação de dissertações, teses e monografias. Elaborado por Anneliese Carneiro da Cunha, Maria Julia de A. L. Freddi, Maria F. Crestana, Marinalva de Souza Aragão, Suely Campos Cardoso, Valéria Vilhena. 3a ed. São Paulo: Divisão de Biblioteca e Documentação; 2011.

Abreviaturas dos títulos dos periódicos de acordo com List of Journals Indexed in Index Medicus. 
SUMÁRIO

Lista de figuras

Lista de tabelas

Lista de abreviaturas e siglas

RESUMO

SUMMARYIABSTRACT

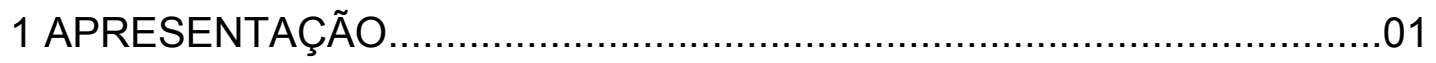

2 INTRODUÇÃO

3 OBJETIVO.

4 MÉTODOS

4.1 Participantes

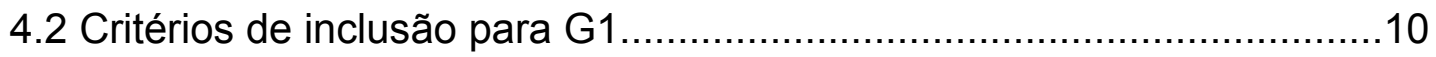

4.3 Critérios de inclusão para G2 ........................................................11

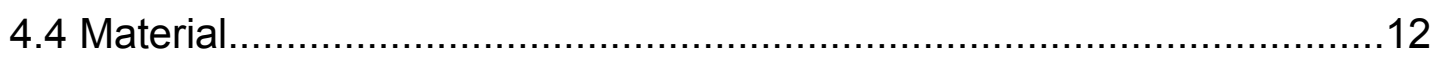

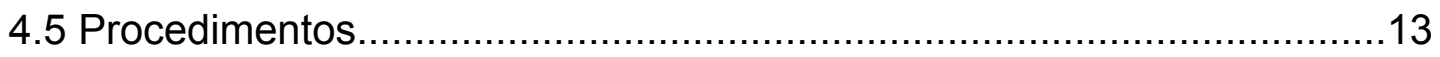

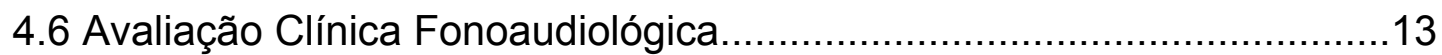

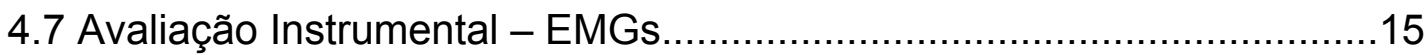

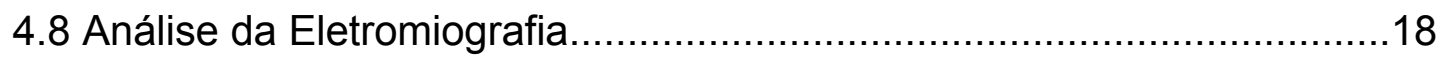

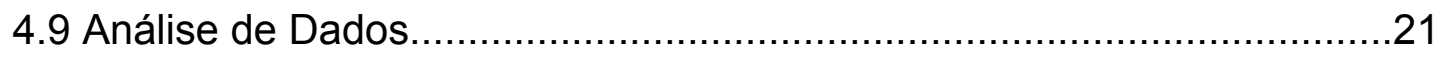

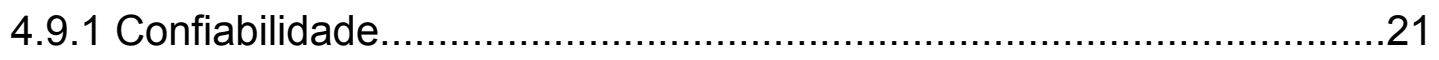

5 RESULTADOS

6 DISCUSSÃO

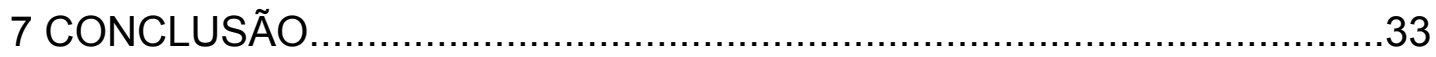

8 ANEXOS

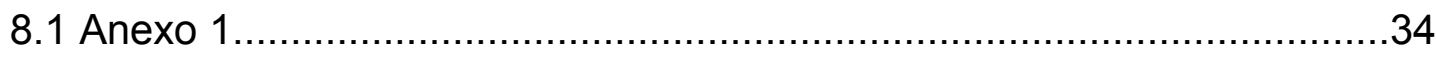




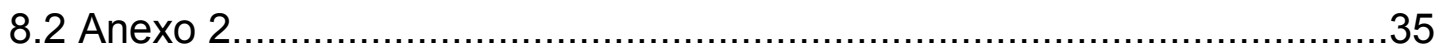

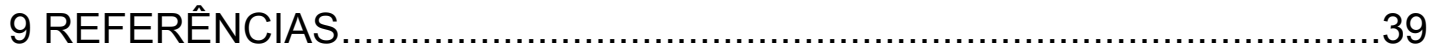


LISTA DE ABREVIATURAS E SIGLAS

AMIOFE - Protocol of orofacial myofunctional evaluation with scores

ASHA NOMS - American Speech-Language-Hearing Association National Outcome Measurement System

CAPPesq HCFMUSP Comissão de Ética para Análise de Projetos de Pesquisa do Hospital das Clinicas

CTG - Citosina, Timina e Guanina

DM1 - Distrofia Miotônica tipo 1

DMPK - Gene da Proteína Quinase

DMS - Doença miotônica de Steinert

DP - Desvio Padrão

EMGs - Eletromiografia de Superfície

FAPESP - Fundação de Amparo à Pesquisa do Estado de São Paulo

FMUSP - Faculdade de Medicina da Universidade de São Paulo

GC - Grupo Controle

GP - Grupo Pesquisa

HCFMUSP - Hospital das Clínicas da Faculdade de Medicina da Universidade de São Paulo

ICHC - Instituto Central do Hospital das Clínicas

LIF-FFFD - Laboratório de Investigação Fonoaudiológica da Fluência, Funções da Face e Disfagia

$\mu \mathrm{V}-$ Microvolts 
MEL - Musculatura extrínseca da larínge

MS - Músculo masseter

OO - Músculo orbicular da boca

RMS - root mean square

SH - Musculatura suprahioidea

TTIII - Treinamento Técnico III 


\section{LISTA DE FIGURAS}

Figura 1 - Posicionamento dos eletrodos................................................17

Figura 2 - Sinal eletromiográfico retificado da deglutição de 16,5ml - G1...19

Figura 3 - Sinal eletromiográfico retificado da deglutição de 16,5ml - G2...20 


\section{LISTA DE TABELAS}

Tabela 1 - Caracterização dos grupos quanto a idade.

Tabela 2 - Comparação entre grupos para o AMIOFE

Tabela 3 - Comparação entre grupos para amplitude e duração da ativação muscular. 24

Tabela 4 - Comparação intragrupos para amplitude e duração da ativação muscular nos diferentes volumes ofertados 26 
RESUMO

ERCOLIN, B. Caracterização da deglutição em portadores de distrofia miotônica de Steinert [dissertação]. São Paulo: "Faculdade de Medicina, Universidade de São Paulo"; 2012.

INTRODUÇÃO: A disfagia orofaríngea e os distúrbios de motilidade esofágica são considerados as mais importantes causas de pneumonia aspirativa em pacientes com distrofia miotônica. O objetivo deste estudo foi avaliar as características clínicas da motricidade orofacial e a deglutição de indivíduos com distrofia miotônica (DM1), utilizando um protocolo clínico padronizado e eletromiografia de superfície (EMGs). MÉTODO: Os participantes foram divididos em dois grupos: G1-composto por 20 adultos com DM1; G2-composto por 20 voluntários saudáveis, os participantes foram pareados por idade e gênero com G1 para a análise estatística. Foi realizada a avaliação das estruturas e funções orofaciais, utilizando um protocolo clínico padronizado, e mensurada a atividade mioelétrica da deglutição por meio da EMGs, com eletrodos localizados em quatro grupos musculares: (1) orbicular da boca, (2) masseter, (3) musculatura suprahioidea e (4) extrínseca da laringe. A atividade mioelétrica foi medida durante o repouso muscular e durante a deglutição de saliva e de $16,5 \mathrm{ml}$ e $20 \mathrm{ml}$ de água. Os traçados da EMGs foram avaliados durante o inicio (onset), pico e o término (offset), dos evento da deglutição. A análise estatística incluiu a ANOVA de duplo fator para intragrupos e intergrupos e o teste de Bonferroni para correções de comparações múltiplas. RESULTADOS: Pacientes com DM1 apresentaram déficits em posição, postura e mobilidade dos órgãos miofuncionais orofaciais, e nas funções de mastigação e deglutição. Além disso, os resultados da EMGs para diferentes tarefas de deglutição indicaram maior atividade muscular do orbicular da boca e maior duração da ativação muscular para os músculos: orbicular da boca, masseter e extrínseco de laringe. Não foi observado aumento significativo na amplitude da EMGs, nos pacientes com DM1, quando comparado aos resultados obtidos no teste de deglutição normal com o teste de estresse. CONCLUSÕES: A maior duração da deglutição na EMGs no grupo DM1, possivelmente está relacionada a miotonia e/ou incoordenação dos músculos envolvidos no processo da deglutição ou pode estar relacionado a uma adaptação fisiológica para uma deglutição segura. A identificação precoce dos distúrbios da deglutição permite reabilitação precoce oral, o que poderia diminuir o risco de pneumonia por aspiração nesta população.

Descritores: Disfagia; Distrofia Miotônica; Eletromiografia de Superfície; Deglutição; Transtornos de deglutição. 


\section{SUMMARYIABSTRACT}

ERCOLIN, B. Characterization of swallowing in patients with myotonic dystrophy of Steinert [dissertation]. São Paulo: "Faculdade de Medicina, Universidade de São Paulo"; 2012.

INTRODUCTION: Oropharyngeal dysphagia and oesophageal motility disorders were found to be the most important reasons causing aspiration pneumonia in patients with myotonic dystrophy. The purpose of this report was to evaluate clinical characteristics of the oral motor movements and swallowing of individuals with myotonic dystrophy type 1 (DM1), using a standardized clinical protocol and surface electromyography (sEMG). METHOD: Participants were 40 individuals divided in two groups: G1composed by 20 adults with DM1; G2- composed by 20 healthy volunteers paired by age and gender to individuals in G1. Participants of all groups underwent clinical assessment of the orofacial structures and functions using a standardized clinical protocol. The myoelectric activity of swallowing was measured using sEMG. Four muscle groups were examined: (1) the orbicularis oris superior and inferior; (2) the masseter; (3) the submental muscle group; and (4) the laryngeal strap muscles. Muscle activity was measured during rest, during dry swallows and during the swallowing of $16.5 \mathrm{ml}$ and $20 \mathrm{ml}$ of water. Surface EMG traces were evaluated for onset, peak and offset of activity during swallow events. The statistical analysis included the one-way ANOVA with two factors for within and between group comparisons and the Bonferroni correction for multiple comparisons. RESULTS: Patients with DM1 presented deficits in posture, position and mobility of the oral motor organs, as well as compromised mastication and deglutition. Moreover, sEMG results for different swallowing tasks indicated higher muscle activity for the orbicularis oris and longer durations of muscle activation for the orbicularis oris, masseter and laryngeal strap muscles. When considering within group comparisons, DM1 patients did not present a significant increase of SEMG amplitude during the stress test in comparison with the normal swallow test. CONCLUSION: Compared to healthy individuals, patients with DM1 presented longer times to pass a bolus from the oral cavity to the esophagus. The larger duration of SEMG in the DM1 group is possibly related to myotonia and/or incoordination of the muscles involved in the swallowing process or could reflect a physiological adaptation for safe swallowing. Early identification of swallowing disorders enables early oral rehabilitation, which in turn could decrease the risk of aspiration pneumonia in this population.

Keywords: Dysphagia - Myotonic dystrophy - Surface electromyography Deglutition - Deglutition disorders. 


\section{APRESENTAÇÃO}

Tenho interesse pelos distúrbios da deglutição desde a minha graduação em Fonoaudiologia (2001-2004), principalmente naqueles decorrentes de patologias de base progressiva e com prognósticos incertos.

Em 2005, cursei o Aprimoramento em Fonoaudiologia Hospitalar no Instituto de Infectologia Emilio Ribas da Faculdade de Medicina da Universidade de São Paulo - FMUSP onde vivenciei maior proximidade com os pacientes hospitalizados e possibilitando aprimorar meu conhecimento na área da disfagia.

No ano seguinte, me candidatei para vaga no Curso de Especialização em Fonoaudiologia, com Núcleo Especifico em Processamento Neuromotor da Fala e da Deglutição, do Curso de Fonoaudiologia da FMUSP. Essa especialização seria desenvolvida no Laboratório de Investigação Fonoaudiológica da Fluência, Funções da Face e Disfagia (LIF-FFFD) do Departamento de Fisioterapia, Fonoaudiologia e Terapia Ocupacional da FMUSP, coordenado pela Professora Claudia Regina Furquim de Andrade. No dia da entrevista para a seleção do curso, a Profa. Claudia Andrade, disse a todos em voz alta: "Pelo fato de vocês virem até aqui já são profissionais diferenciados. Aos que não forem selecionados, não desistam do caminho, e aos selecionados, parabéns e vamos seguir em mais uma jornada". Neste momento eu tive a certeza de que queria fazer 
parte daquela história. No LIF-FFFD tive a oportunidade de conhecer a Fonoaudióloga Assistente, a então Doutora Fernanda Chiarion Sassi.

A Dra Fernanda Chiarion Sassi estava iniciando sua pesquisa de Pós-Doutorado pela FAPESP (Processo $n^{\circ}$ 03/13526-9) intitulado: A efetividade da realimentação no tratamento da gagueira de desenvolvimento: estudos comparativos. Interessei-me por sua pesquisa, pois nela seria utilizado o exame de eletromiografia de superfície (EMGs). Naquela época a EMGs era um instrumento ainda pouco utilizado na Fonoaudiologia brasileira. O LIF-FFFD sempre teve como característica marcante a seriedade em suas pesquisas e a preocupação com a construção da Fonoaudiologia Baseada em Evidências. Esse novo projeto seria mais uma importante contribuição para a Fonoaudiologia. Ao perceber meu interesse, a Dra Fernanda Chiarion Sassi me incentivou a pleitear uma bolsa de Treinamento Técnico III (TTIII) da FAPESP, na qual seria desenvolvido todo o treinamento necessário. Meu pedido foi aceito.

A especialização teve seu término no inicio do ano de 2007, e a bolsa de Treinamento Técnico III em julho de 2007. Durante esse período, aprendi com mais propriedade sobre o processamento neuromotor da deglutição, sobre as peculiaridades do exame de EMGs nas funções estomatognáticas, e ainda sobre metodologia cientifica. 
Desde 2005 a Profa. Dra. Claudia Regina Furquim de Andrade assumiu o Serviço de Fonoaudiologia no Instituto Central do Hospital das Clínicas (ICHC) da FMUSP. Nesta época foi iniciado um mapeamento da necessidade de profissionais fonoaudiólogos em todo o ICHC. O Serviço começou a ser ampliado, estruturado e conhecido pelo profissionalismo da equipe.

No ano de 2009, a médica neurologista Dra Suely Kazue Nagahashi Marie, sugeriu a inserção de um profissional fonoaudiólogo no Ambulatório de Miopatias do ICHC, para fins de pesquisa e atuação multidisciplinar junto aos portadores dessas patologias. A Profa Dra Claudia Regina Furquim de Andrade me direcionou para fazer a parceria entre o Ambulatório de Miopatias e o Serviço de Fonoaudiologia.

O Ambulatório de Miopatias apresentava uma grande demanda de pacientes com distúrbios de mastigação, deglutição e voz, com patologias de base progressiva, e com prognósticos incertos, despertando assim, meu intenso empenho em compreender e buscar soluções para os distúrbios fonoaudiológicos que os pacientes apresentavam. Iniciei um estudo piloto envolvendo a avaliação da deglutição em portadores da Distrofia Miotônica de Steinert (DMS). Percebemos que poderia ser um estudo mais aprofundado por ser um tema tão pouco explorado pela Fonoaudiologia. Pacientes com DMS apresentam, dentre outras características, maior risco 
de broncoaspiração de alimentos, sendo o fonoaudiólogo um dos responsáveis por tratar essa sintomatologia.

Após estudo aprofundado sobre a temática e conhecendo melhor as características da doença, comecei a me questionar até que ponto o fenômeno miotônico, presente nesses pacientes, poderia comprometer a deglutição, visto que esses indivíduos apresentam maior propensão à aspiração bronco pulmonar. Como pode o fenômeno miotônico atuar na musculatura envolvida na deglutição? A deglutição está prejudicada ou será adaptada?

Ingressei no mestrado em 2010, pelo programa de Ciências da Reabilitação do Departamento de Fisioterapia, Fonoaudiologia e Terapia Ocupacional da FMUSP, com o projeto intitulado: 'Caracterização da deglutição em portadores de distrofia miotônica de Steinert".

Com este trabalho, espero contribuir para melhor compreensão da relação entre a distrofia miotônica de Steinert e a deglutição, orientando os profissionais da saúde sobre as peculiaridades, dificuldades e adequações da deglutição destes indivíduos.

Esta dissertação é apresentada na forma de um artigo científico, sendo que este já foi submetido a um periódico internacional arbitrado da área. O artigo submetido é intitulado: "Oral motor movements and swallowing 
in patients with Myotonic Dystrophy Type 1". Por esse motivo, o título do artigo não corresponde ao título da dissertação, uma vez que os dados apresentados e discutidos representam um recorte do projeto de pesquisa original. Optamos pela não mudança de título da dissertação porque entendemos que o texto aqui apresentado é abrangido pelo título original. Os dados obtidos ao longo do estudo, permitirão desdobramentos tanto em novos artigos quanto para a continuidade na pesquisa de doutoramento. 


\title{
MOVIMENTOS OROFACIAIS E DEGLUTIÇÃO EM PACIENTES COM DISTROFIA MIOTONICA TIPO 1
}

\author{
INTRODUÇÃO
}

A Distrofia Miotônica de Steinert ou Distrofia Miotônica Tipo 1 (DM1),é uma miopatia genética multisistêmica, transmitida por herança autossômica dominante. O mecanismo molecular responsável pela DM1, cujo gene foi mapeado em 19q, é uma expansão do trinucleotídeo: Citosina, Timina e Guanina (CTG), no gene da proteína quinase $(\mathrm{DMPK})^{1,2}$. O tamanho da expansão do trinucleotídeo está relacionado com a idade de inicio da doença e com a severidade do fenótipo. Sendo assim, nas gerações sucessivas, a doença apresenta seus sintomas mais precocemente e se torna progressivamente mais grave (fenômeno de antecipação) ${ }^{3}$.

A DM1 é considerada a mais comum das distrofias em adultos, com uma prevalência estimada entre 2,1 e 14,3 por 100.000 habitantes em todo o mundo ${ }^{2,4-6}$. Clinicamente, a DM1 é caracterizada pela miotonia (atraso ou dificuldade do relaxamento do músculo após contração), fraqueza muscular progressiva e atrofia, sobretudo na face (com manifestações orais e maxilofaciais) e pescoço, ptose palpebral, partes distais de membros, problemas gastrointestinais, insuficiência respiratória e distúrbios cardíacos ${ }^{7-}$ 9 
A fraqueza muscular e a miotonia são responsáveis por alterações na produção da fala de alguns pacientes (por exemplo: disartria flácida) ${ }^{10,13} \mathrm{~A}$ qualidade da fala depende da condição e gravidade da doença. Geralmente, esses pacientes apresentam alterações na fala como: monotonia, hipernasalidade, rouquidão, velocidade de fala lentificada, incoordenação pneumofonoarticulatória e inteligibilidade diminuida ${ }^{14,15}$.

A pneumonia aspirativa é uma das causas de morte mais comuns nos pacientes com $\mathrm{DM} 1^{16}$. De acordo com a literatura, estudos radiográficos e de manometria, constataram que as principais causas da pneumonia aspirativa são: disfagia orofaríngea e distúrbios de motilidade esofágica ${ }^{17-20}$. A avaliação eletrofisiológica da deglutição orofaríngea (combinação da eletromiografia de superfície dos músculos suprahioideos e eletromiografia com agulhas do músculo cricofaríngeo) indica que indivíduos com DM1 apresentam o reflexo de deglutição e tempo de elevação de laringe significativamente aumentados ${ }^{21}$. A avaliação da nasofibrolaringoscopia da deglutição também indicou alterações no processo de deglutição para todas as consistências, evidenciando episódios de penetração e aspiração traqueal de alimentos ${ }^{22}$.

Na DM1, medidas preventivas globais de saúde são imprescindíveis. Considerando os pacientes com distrofia miotônica, o sintoma de disfagia geralmente não é percebido até os estágios mais avançados da doença ${ }^{20}$. Embora não exista cura, o gerenciamento efetivo da doença pode reduzir 
significativamente a morbidade e mortalidade desses pacientes ${ }^{23}$. O videodeglutograma é considerado o exame padrão-ouro de avaliação da deglutição ${ }^{24}$. Porém, este exame tem um alto custo e não pode ser realizado com freqüência ${ }^{25}$. Dado este fato, alguns autores, sugerem a eletromiografia de superfície (EMGs) como um teste não-invasivo, de baixo custo e de fácil realização para avaliação da deglutição ${ }^{26-29}$. 
OBJETIVO

O objetivo deste estudo foi avaliar as características clínicas da motricidade orofacial e a deglutição de indivíduos com distrofia miotônica (DM1), utilizando um protocolo clínico padronizado e eletromiografia de superfície (EMGs). 


\section{MÉTODOS}

Trata-se de um estudo caso-controle, transversal prospectivo. Essa pesquisa foi aprovada pela Comissão de Ética da Instituição (CAPPesq HCFMUSP 0350/10 - ANEXO 1). Os participantes somente deram início aos procedimentos da pesquisa após a assinatura do termo de consentimento livre e esclarecido (ANEXO 2). O período de coleta dos dados foi de junho de 2010 a julho de 2011.

\section{Participantes}

Fizeram parte desse estudo 40 participantes, de ambos os sexos. Foram divididos em dois grupos distribuídos da seguinte forma: G1 composto por 20 portadores de DM1, que freqüentavam o ambulatório de Miopatias do Hospital das Clínicas da Faculdade de Medicina da Universidade de São Paulo (HCFMUSP), selecionados de forma randômica, 8 do gênero masculino e 12 do gênero feminino, com média de idade de 36,05 anos; G2 composto por 20 indivíduos normais, sendo 8 do gênero masculino e 12 do gênero feminino, com média de idade de 34,75 anos.

Critérios de inclusão para G1:

Foram considerados critérios de inclusão para participantes de G1:

a) indivíduos com diagnóstico de DM1. O diagnóstico foi obtido por método clínico e molecular realizado no ambulatório de Miopatias do HCFMUSP; 
b) não apresentar quaisquer déficits cognitivos ou auditivos, conforme prontuário médico;

c) adultos maiores de 18 anos;

d) não ter sido submetido a qualquer procedimento cirúrgico de cabeça e pescoço;

e) não ter sido submetido a qualquer procedimento cirúrgico de esôfago;

f) não ter realizado tratamento fonoaudiológico prévio.

g) apresentar pontuação de 6 ou 7 na escala do nível da deglutição da American Speech-Language-Hearing Association National Outcome Measurement System (ASHA NOMS), ou seja, pontuação indicativa de que o individuo apresenta uma deglutição segura e que se alimenta de forma independente ${ }^{30,31}$.

Critérios de inclusão para G2:

Foram considerados critérios de inclusão para participantes de G2:

a) indivíduos que voluntariamente aceitaram participar da pesquisa;

b) não apresentar histórico familiar para DM1;

c) não apresentar quaisquer déficits comunicativos, neurológicos, cognitivos ou auditivos;

c) não apresentar queixa e/ou alteração das funções orofaciais;

d) não ter sido submetido a qualquer tipo de procedimento cirúrgico de cabeça e pescoço;

e) não ter sido submetido a qualquer procedimento cirúrgico de esôfago;

f) ausência de mal oclusão severa; 
g) sem uso de aparatologia ortodôntica;

h) não ter realizado tratamento fonoaudiológico prévio.

\section{$\underline{\text { Material }}$}

Para realização da EMGs foi utilizado aparelho Eletromiógrafo - Miotool 400 com 4 canais, calibrados em 500 microvolts $(\mathrm{mV})$ com filtro do tipo passa banda $(20-500 \mathrm{~Hz})$ e ganho de 100 vezes, com baixo nível de ruído (< $5 \mu \mathrm{V}$ RMS) considerado pela THE INTERNATIONAL SOCIETY OF ELECTROPHYSIOLOGICAL KINESIOLOGYY - ISEK (s.d.) como o recomendável ${ }^{32}$.

O software utilizado para a captação e processamento do exame de EMGs foi o aplicativo Miograph 2.0 do fabricante Miotec $®$ Equipamentos Biomédicos que faz aquisição, armazenamento e processamento on-line de sinais e é executado sob o sistema operacional Windows XP. Os sinais da atividade elétrica dos movimentos musculares foram captados por eletrodos bipolares de superfície $\mathrm{Ag} / \mathrm{AgCl}$ descartáveis, modelo SDS500, duplos, fixados com fita transpore (fabricante $3 \mathrm{M}$ ). Foram utilizados gaze, álcool $70 \%$, água filtrada, copos e seringas descartáveis de $20 \mathrm{ml}$. Cabe ressaltar, que a água utilizada estava em temperatura ambiente a fim de evitar a indução ao fenômeno miotônico das estruturas envolvidas na deglutição.

Foi utilizado para a avaliação das estruturas e funções orofaciais, o Protocol of orofacial myofunctional evaluation with scores - AMIOFE $^{33}$ e pão 
francês. Para a gravação das imagens da avaliação clínica, foi utilizada uma câmera digital Panasonic DMC-FS3LB-P.

\section{Procedimentos}

Todos os participantes foram submetidos à avaliação fonoaudiológica das funções orofaciais em dois dias, em sessões de 40 minutos. A metodologia e procedimentos adotados para a avaliação dos participantes deste estudo encontram-se descritos abaixo:

\section{Avaliação Clínica Fonoaudiológica}

Os indivíduos foram examinados, enquanto sentado em uma cadeira em uma sala com iluminação apropriada, e aplicado o protocolo padronizado Protocol of orofacial myofunctional evaluation with scores - AMIOFE ${ }^{33}$. Este protocolo foi construído com base em modelos anteriores de avaliação, com a adição de escalas numéricas que refletem as características físicas e comportamentos orofaciais dos indivíduos.

A avaliação foi realizada, de acordo com o protocolo, e os componentes do sistema estomatognático, ou seja, lábios, língua, mandíbula e bochechas, foram avaliados em termos de mobilidade e desempenho durante as funções de deglutição e de mastigação. Os indivíduos foram avaliados individualmente por inspeção visual e complementada pelas imagens gravadas na câmera digital. Para a avaliação da mobilidade, os indivíduos foram solicitados a realizar movimentos isolados dos lábios, 
língua, mandíbula e bochechas. $\mathrm{Na}$ análise é considerado normal movimentos isolados de cada componente, precisos e sem tremor. Deve ser considerado como alteração: falta de precisão no movimento, tremor, movimentos associados de outros componentes (exemplo, lábios que acompanham os movimentos da língua), e ainda, a incapacidade para realizar o movimento. O examinador atribuiu escores utilizando uma escala de 3 pontos: $3=$ normal, 2 = capacidade insuficiente e $1=$ ausência de capacidade ou de ser incapaz de executar a tarefa. Na deglutição o padrão é considerado normal, quando a língua estiver contida na cavidade oral, ocorrendo contração dos músculos elevadores e vedamento anterior da cavidade oral sem esforço.

Para a mastigação, o sujeito foi instruído a mastigar os alimentos de forma habitual. $\mathrm{Na}$ análise de imagens gravadas em vídeo, os seguintes parâmetros foram considerados: mastigação alternada bilateral, simultânea bilateral, crônica unilateral (95\% do tempo no mesmo lado da cavidade), ou anterior; preferência de mastigação unilateral $(66 \%$ do tempo no mesmo lado) ou anterior, e o tempo total necessário para consumir o alimento foi medido com um cronômetro digital (Nike, WR0016-001P - 10 LAP). Tal como descrito no protocolo específico, de mastigação e função de deglutição foram pontuados como normal (3), disfunção leve (2), ou disfunção grave (1). Outros comportamentos (por exemplo, movimento e/ou alteração da postura da cabeça e de outras partes do corpo, escape de alimentos, e movimentos mandibulares descoordenados) foram definidos como normal 
quando eles receberam uma pontuação de 2 e alterados quando eles receberam uma pontuação de 1 .

Todos os participantes foram avaliados por dois fonoaudiólogos experientes. Os examinadores foram devidamente treinados na avaliação miofuncional orofacial e apresentariam um alto nível de concordância (> $0,89)$.

Avaliação instrumental - EMGs:

Todos os exames de EMGs foram realizados pelo Serviço de Fonoaudiologia do Instituto Central do HCFMUSP e pelo mesmo fonoaudiólogo com experiência na área, nas mesmas condições ambientais. Previamente à coleta dos dados o equipamento foi calibrado conforme normas estabelecidas pela THE INTERNATIONAL SOCIETY OF ELECTROPHYSIOLOGICAL KINESIOLOGY ISEK ${ }^{32}$ O posicionamento dos eletrodos obedeceu à técnica de colocação do ponto médio do ventre muscular na direção longitudinal do feixe muscular na posição mesodistal do músculo conforme sugerido por Soderberg e Cook ${ }^{34}$; onde se observa maior amplitude de sinal para este tipo de eletrodo. Para garantir o correto posicionamento dos eletrodos, foi realizada a identificação dos músculos por meio da palpação durante o repouso e na contração máxima - foi solicitada a máxima intercuspidação dentária e deglutição. Após esta etapa, a função muscular foi testada para a verificação de possíveis erros de posicionamento e realizada nova colocação do eletrodo, quando necessário. 
Para a coleta dos dados eletromiográficos, todos participantes estavam confortavelmente sentados em uma cadeira, com as costas apoiadas, pés apoiados no chão, mãos apoiadas nos membros inferiores, cabeça posicionada adequadamente (Plano de Frankfurt paralelo ao chão), olhos abertos e buscando um ponto fixo pré-determinado. Todos os indivíduos foram orientados quanto ao teste. A pele da face foi preparada utilizando gaze embebida em álcool $70 \%$ para remover a oleosidade e as células mortas presentes no local e realizada tricotomia local, ambos para garantir adequada impedância durante a realização do exame. Os sinais captados foram analisados em root mean square (RMS) e expressos em microvolts $(\mu \mathrm{V})$. O cabo de referência (cabo terra) foi conectado ao eletrodo e fixado sobre o pulso direito.

De acordo com a metodologia proposta por Vaiman et al. (2004), foi verificada a atividade mioelétrica dos seguintes músculos: (1) orbicular da boca (OO); (2) masseter (MS); (3) musculatura suprahioidea (SH) que inclui os músculos digástrico, milohioideo e geniohioideo; e (4) musculatura extrínseca da larínge (MEL) incluindo os músculos infrahioideo e tirohioideo. Estes músculos foram selecionados por serem superficiais e por estarem envolvidos nas fases oral e faríngea da deglutição.

A posição dos eletrodos pode ser observada na Figura 1: (1) dois eletrodos de superfície no ângulo direito da boca, um acima do lábio superior 
e outro abaixo do lábio inferior (localização OO); (2) dois eletrodos paralelos às fibras do músculo masseter no lado esquerdo da face (localização MS); (3) dois eletrodos abaixo do queixo na linha mediana para gravar a atividade mioelétrica da musculatura $\mathrm{SH}$; (4) dois eletrodos na lateral esquerda da cartilagem tireóide para gravar a atividade mioelétrica dos músculos da laringe (MEL).

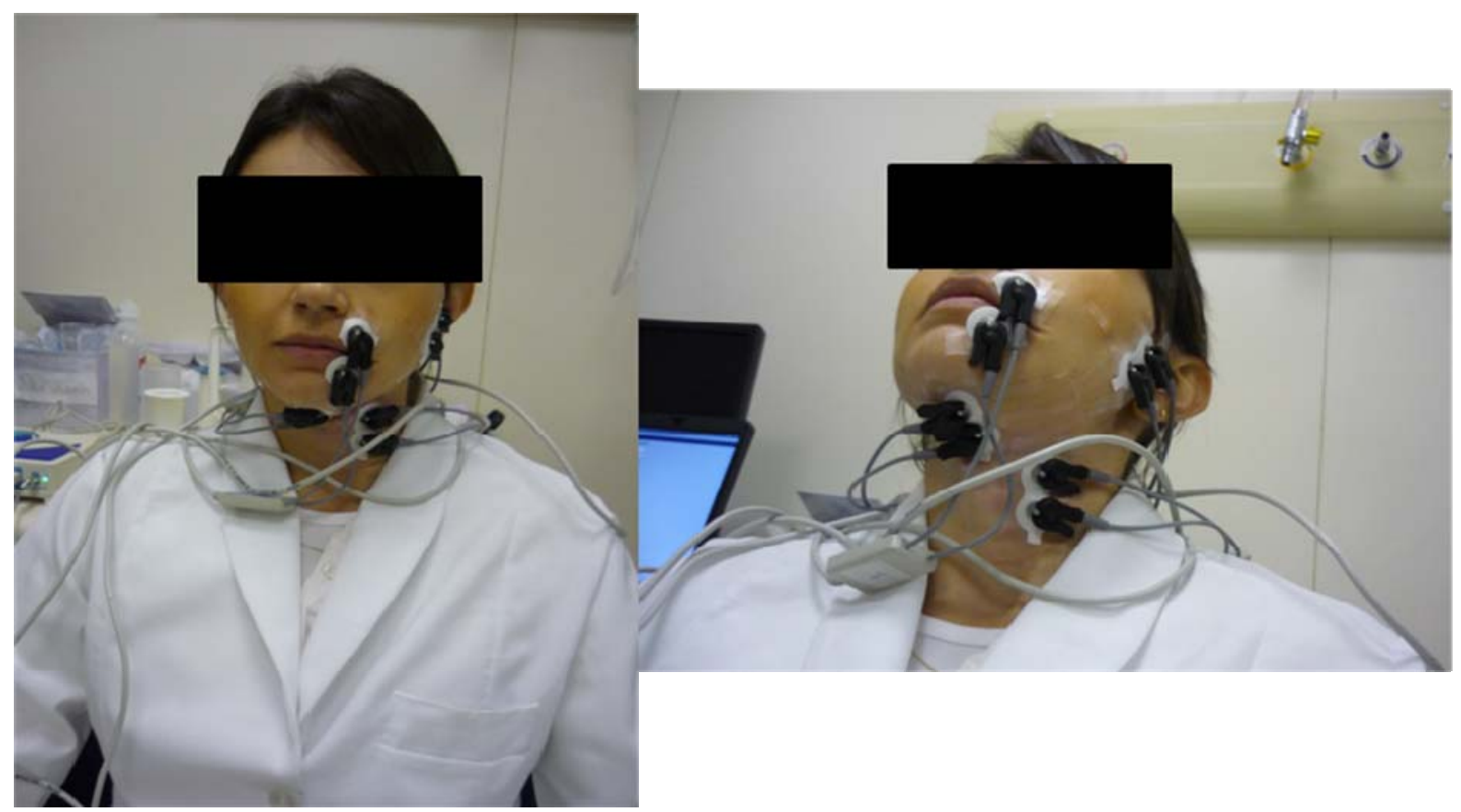

Fig. 1. Posicionamento dos eletrodos

A avaliação eletromiográfica foi realizada em duas etapas:

a) Repouso - cada participante foi instruído a permanecer o mais relaxado possível durante 1 minuto. Após esse tempo foram gravados 30 segundos de atividade muscular dos músculos $\mathrm{OO}, \mathrm{MS}, \mathrm{SH}$ e MEL;

b) Avaliação da deglutição: três testes de deglutição foram solicitados por três vezes: 1) Deglutição voluntária de saliva: O participante 
recebeu a seguinte instrução - "Engula a saliva que está agora na sua boca"; 2) Oferta de água no copo de 16,5 ml de água. O participante recebeu a seguinte instrução "Beba toda a água em apenas um gole"; 3) Oferta de $20 \mathrm{ml}$ de água no copo. O participante recebeu a seguinte instrução: "Beba toda a água em apenas um gole". Este último teste visa verificar a habilidade de deglutição de um maior volume de bolo.

Desta forma, foram obtidas um total de 9 deglutições por participante, perfazendo um total de 360 análises.

\section{Análise da eletromiografia de superfície}

Para a análise dos resultados da EMGs foi utilizado a análise do domínio temporal. Neste caso, a informação obtida descreve em que momento o evento ocorreu e qual a amplitude (indicador da magnitude da atividade muscular) de sua ocorrência. Na situação de repouso, os valores obtidos representam a média (RMS) da atividade eletromiográfica observada em 30 segundos. A duração da atividade muscular durante as tarefas de deglutição foi obtida pela seleção do trecho representativo da ativação muscular (situação on, pico e off). Esse trecho foi selecionado com o cursor do próprio programa de eletromiografia e convertido em microvolts $(\mu \mathrm{V})$. 


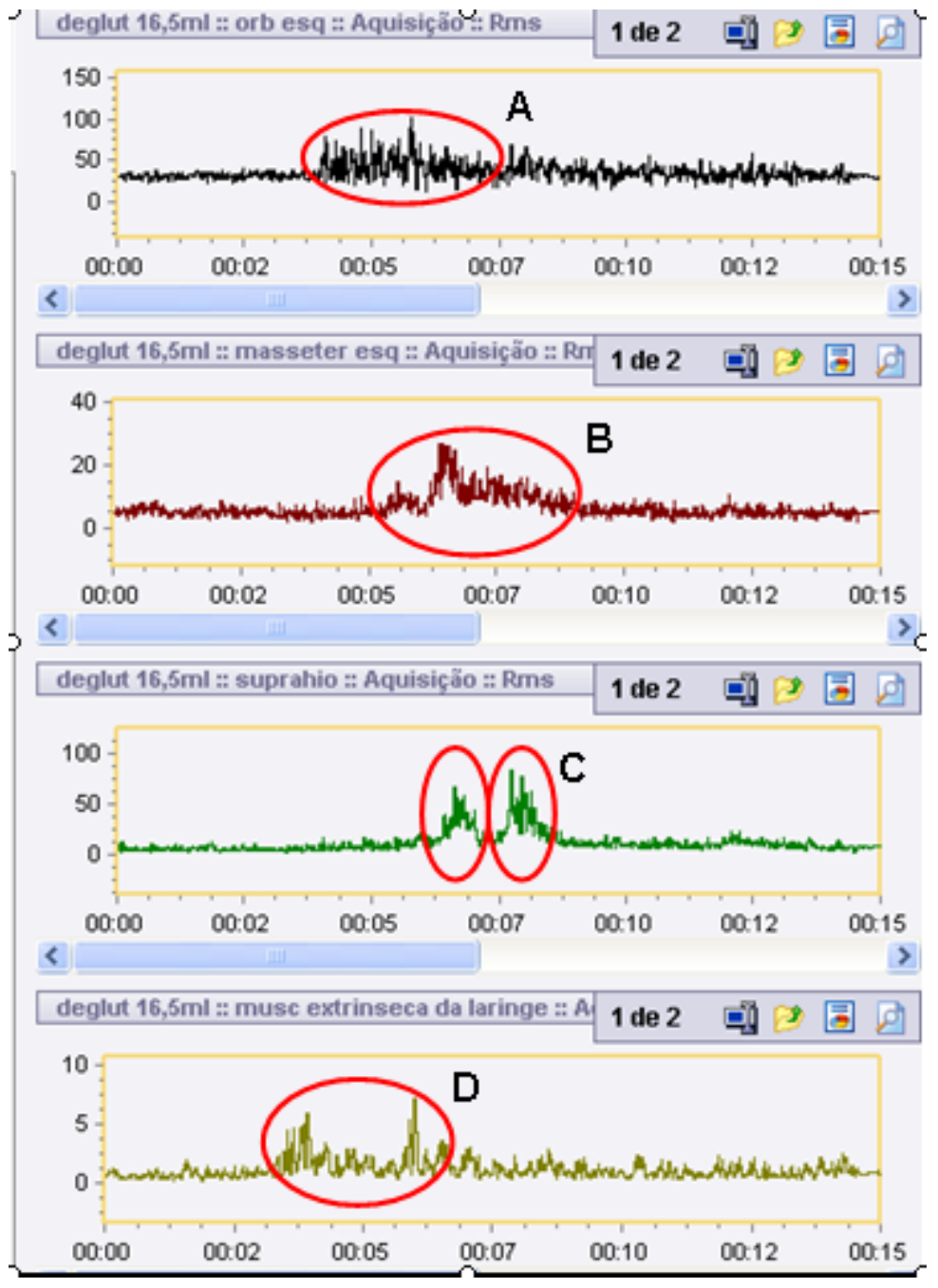

Fig. 2. Sinal eletromiográfico retificado da deglutição de 16,5ml - G1.

Legenda: A - trecho de análise do músculo orbicular da boca.

$B$ - trecho de análise do músculo masseter.

C - trecho de análise da musculatura suprahioidea

D - trecho de análise da musculatura extrínseca da laringe. 


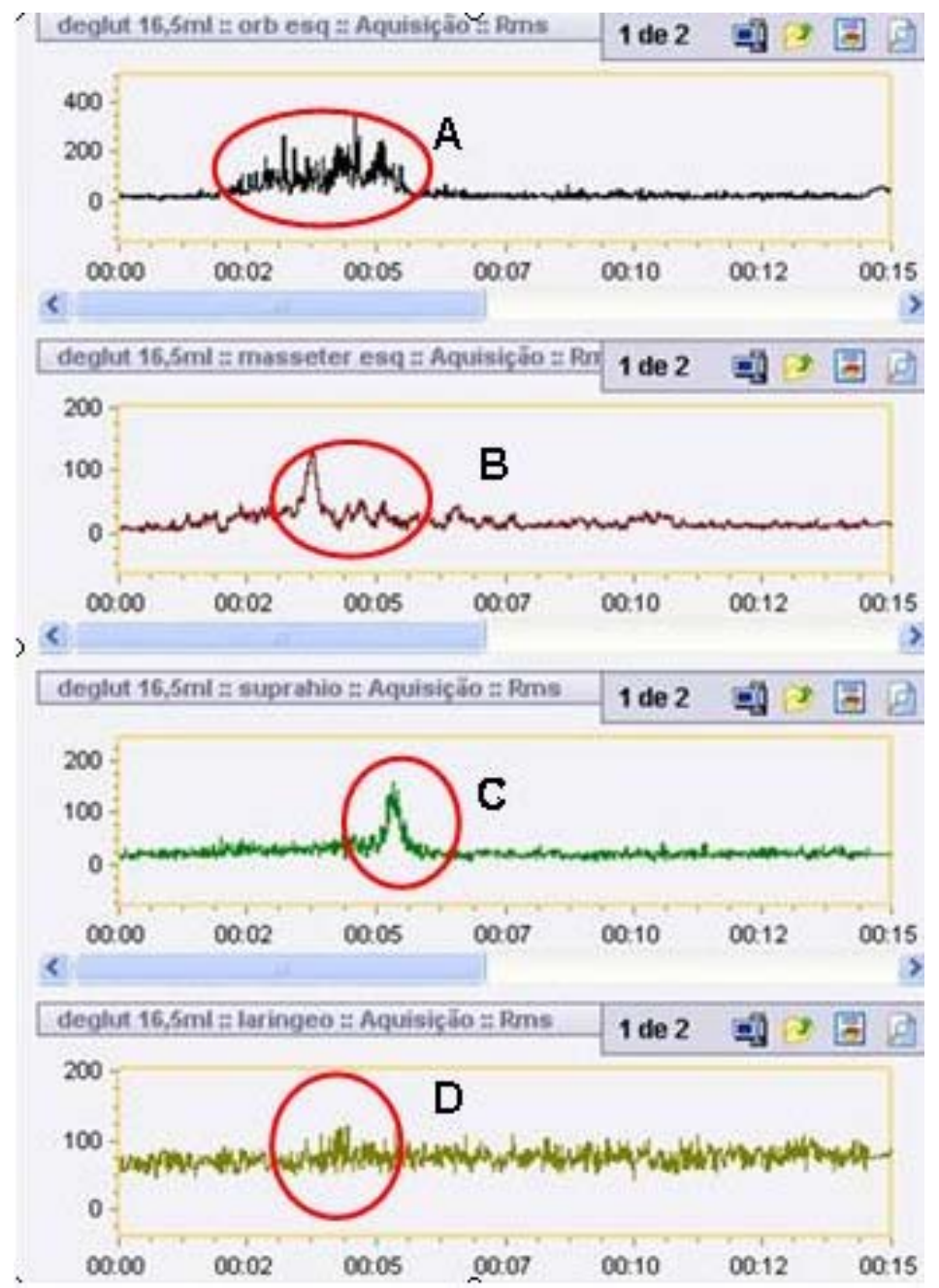

Fig. 3. Sinal eletromiográfico retificado da deglutição de 16,5ml - G2.

Legenda: A - trecho de análise do músculo orbicular da boca.

$B$ - trecho de análise do músculo masseter.

C - trecho de análise da musculatura suprahioidea

D - trecho de análise da musculatura extrínseca da laringe. 


\section{$\underline{\text { Confiabilidade }}$}

Com base na literatura relacionada, que aponta subjetividade na leitura das medidas da EMGs, foi realizada análise de confiabilidade a fim de determinar o índice de concordância entre os examinadores e assim garantir maior fidedignidade das medidas. Para tanto, foram selecionadas randomicamente 30 amostras eletromiográficas de um total de 360 . Essas amostras foram analisadas, independentemente, por dois pesquisadores com experiência na área, cegos ao estudo. O coeficiente de correlação mostrou-se alto para todas as comparações (intervalo de confiança de $95 \%$ $[I C]=0.9345-0.9768)$, indicando alta consistência entre os examinadores .

\section{Análise dos Dados}

As análises estatísticas descritivas e inferenciais foram executadas com o software SPSS versão 17.0. Os pressupostos da distribuição normal em cada grupo e a homogeneidade das variâncias entre os grupos foram avaliados, respectivamente, com o teste de Shapiro-Wilk e com o teste de Levene. Para as variáveis quantitativas dependentes onde foram analisados dois fatores foi utilizada ANOVA de duplo fator com medidas repetidas para um fator. Quando foi necessário realizar comparações múltiplas de médias, utilizou-se do teste de Bonferroni, foi usado para assegurar um nível de significância 0,05 . O teste t de Student foi utilizado para as variáveis onde foi analisado um fator. 


\section{RESULTADOS}

A Tabela 1 , se refere a caracterização da idade dos participantes. A análise estatística demonstra que não houve diferenças significativas entre os grupos quanto a idade.

Tabela 1 - Caracterização dos grupos quanto a idade

\begin{tabular}{lccc}
\hline & MÉDIAS(DP) & $F$ & $p$ \\
& IDADE & & \\
\hline GP & $36,05(8,32)$ & 0,32 & 0,564 \\
GC & $34,55(7,95)$ & 0,32 & 0,564 \\
\hline
\end{tabular}

Legenda: DP: Desvio Padrão; GP: Grupo de Pesquisa; GC:

Grupo Controle.

A Tabela 2 apresenta a descrição dos dados encontrados na avaliação fonoaudiológica clínica, de acordo com o protocolo $\mathrm{AMIOFE}^{33}$. Conforme o esperado, todos os itens avaliados apresentaram diferença significativa na comparação entre os grupos. A mobilidade dos órgãos fonoarticulatórios foi o item que mostrou maior diferença entre os grupos. De maneira geral, o grupo pesquisa apresentou menor pontuação para todos os itens, demonstrando que há alteração na postura e posição, mobilidade, funções de respiração, mastigação e deglutição do sistema estomatognático. 
Tabela 2 - Comparação entre grupos para o AMIOFE

\begin{tabular}{lcccc}
\hline & \multicolumn{4}{c}{ MÉDIAS (DP) } \\
\hline & GP & GC & F & $p$ \\
\hline POSTURA E POSIÇÃO & $11,90(2,24)$ & $15,70(1,49)$ & 4,22 & $<0,001^{*}$ \\
MOBILIDADE & $43,05(8,02)$ & $52,65(3,51)$ & 17,04 & $<0,001^{*}$ \\
FUNÇÕES & $14,40(2,80)$ & $21,80(2,57)$ & 0,09 & $<0,001^{*}$ \\
$\quad$ TOTAL & $69,35(10,15)$ & $90,15(3,91)$ & 25,08 & $<0,001^{*}$ \\
\hline${ }^{*} p$-valores considerados estatisticamente & & & \\
significantes \\
Legenda: DP: Desvio Padrão; GP: Grupo de Pesquisa; GC: Grupo \\
Controle.
\end{tabular}

Na Tabela 3 está apresentada a análise comparativa entre os grupos para a amplitude da EMGs e duração (tempo) da contração muscular. Quanto a amplitude da EMGs não foi evidenciado diferença estatisticamente significante entre os grupos para nenhuma das tarefas de deglutição com água. Apenas na tarefa de deglutição de saliva, o músculo orbicular do GC apresentou maior ativação muscular que o GP.

De acordo com a Tabela 3, GP apresenta um tempo significativamente maior para a realização dos movimentos da deglutição quando comparado ao GC em todas as tarefas de deglutição. A única ressalva foi para a deglutição de saliva, que para todos os músculos, exceto a musculatura extrínseca da laringe, não apresentou diferença estatisticamente significante entre os grupos. 
Tabela 3 - Comparação entre grupos para amplitude e duração da ativação muscular

\begin{tabular}{|c|c|c|c|c|c|c|}
\hline & & & \multicolumn{2}{|c|}{ MÉDIAS (DP) EMGs } & \multirow{2}{*}{$F$} & \multirow{2}{*}{$p$} \\
\hline & & & GP & $\mathrm{GC}$ & & \\
\hline \multirow{12}{*}{$\begin{array}{l}\text { EMGs } \\
\text { (RMS) }\end{array}$} & \multirow{3}{*}{$\mathrm{OO}$} & SALIVA & $2,70(1,32)$ & $4,46(3,64)$ & 4,12 & $0,049^{*}$ \\
\hline & & $16,5 \mathrm{ML}$ & $4,17(2,18)$ & $5,69(3,63)$ & 2,57 & 0,117 \\
\hline & & $20 \mathrm{ML}$ & $4,06(1,86)$ & $5,77(3,45)$ & 3,79 & 0,059 \\
\hline & \multirow{3}{*}{ MS } & SALIVA & $1,90(0,62)$ & $2,37(1,49)$ & 1,68 & 0,203 \\
\hline & & $16,5 \mathrm{ML}$ & $2,08(0,87)$ & $2,91(2,81)$ & 1,57 & 0,218 \\
\hline & & $20 \mathrm{ML}$ & $2,10(0,81)$ & $2,72(2,05)$ & 1,60 & 0,213 \\
\hline & \multirow{3}{*}{$\mathrm{SH}$} & SALIVA & $2,74(1,20)$ & $4,00(2,73)$ & 3,55 & 0,067 \\
\hline & & $16,5 \mathrm{ML}$ & $3,34(1,35)$ & $4,46(2,51)$ & 3,04 & 0,089 \\
\hline & & $20 \mathrm{ML}$ & $3,42(1,87)$ & $4,43(2,22)$ & 2,38 & 0,131 \\
\hline & \multirow{3}{*}{ MEL } & SALIVA & $1,86(0,52)$ & $2,07(0,68)$ & 1,18 & 0,284 \\
\hline & & $16,5 \mathrm{ML}$ & $2,60(1,85)$ & $2,36(0,72)$ & 0,29 & 0,592 \\
\hline & & $20 \mathrm{ML}$ & $2,39(1,59)$ & $2,28(0,64)$ & 0,09 & 0,770 \\
\hline \multirow{12}{*}{$\begin{array}{l}\text { TEMPO } \\
\text { (em } \\
\text { segundos) }\end{array}$} & \multirow{3}{*}{$\mathrm{OO}$} & SALIVA & $2,02(0,68)$ & $1,81(0,32)$ & 1,46 & 0,234 \\
\hline & & $16,5 \mathrm{ML}$ & $3,43(1,06)$ & $2,20(0,76)$ & 17,89 & $<0,001^{*}$ \\
\hline & & $20 \mathrm{ML}$ & $3,64(1,16)$ & $2,21(0,75)$ & 21,15 & $<0,001^{*}$ \\
\hline & \multirow{3}{*}{ MS } & SALIVA & $1,87(0,55)$ & $1,74(0,37)$ & 0,81 & 0,372 \\
\hline & & $16,5 \mathrm{ML}$ & $2,61(0,73)$ & $1,91(0,57)$ & 10,95 & $0,002^{*}$ \\
\hline & & $20 \mathrm{ML}$ & $2,48(0,62)$ & $1,79(0,39)$ & 17,07 & $<0,001^{*}$ \\
\hline & \multirow{3}{*}{$\mathrm{SH}$} & SALIVA & $1,75(0,42)$ & $1,79(0,25)$ & 0,12 & 0,730 \\
\hline & & $16,5 \mathrm{ML}$ & $2,12(0,61)$ & $1,82(0,37)$ & 3,32 & 0,076 \\
\hline & & $20 \mathrm{ML}$ & $2,04(0,59)$ & $1,79(0,42)$ & 2,28 & 0,139 \\
\hline & \multirow{3}{*}{ MEL } & SALIVA & $1,88(0,59)$ & $1,57(0,31)$ & 4,38 & $0,043^{*}$ \\
\hline & & $16,5 \mathrm{ML}$ & $2,34(0,84)$ & $1,66(0,32)$ & 11,19 & $0,002^{*}$ \\
\hline & & $20 \mathrm{ML}$ & $2,17(0,60)$ & $1,62(0,40)$ & 11,43 & $0,002^{*}$ \\
\hline & \multicolumn{6}{|c|}{$\begin{array}{l}\text { Legenda: DP: Desvio Padrão; GP: Grupo de Pesquisa; GC: Grupo Controle; } \\
\text { RMS: root mean square. }\end{array}$} \\
\hline & \multicolumn{6}{|c|}{$\begin{array}{l}\text { OO:músculo orbicular da boca; MS: músculo masseter; } \\
\text { SH:musculatura suprahioidea; MEL:musculatura extrínseca da } \\
\text { laringe }\end{array}$} \\
\hline
\end{tabular}

$\mathrm{Na}$ Tabela 4 são apresentados os resultados da análise estatística para a comparação intragrupos das variáveis da EMGs e do tempo de duração da ativação muscular. Quanto a amplitude da ativação muscular do 
grupo GP, observou-se diferença significante para o músculo orbicular e para os músculos extrínsecos da laringe. Em ambos os casos, a ativação muscular foi menor durante a deglutição da saliva (OO: Saliva x 16,5ml $p=0,016^{*}$; Saliva $\times 20 \mathrm{ml}-p=0,45^{*} ; 16,5 \mathrm{ml} \times 20 \mathrm{ml}-p=1,000 ;$ MEL: Saliva $\times$ $16,5 \mathrm{ml}-p=0,019^{*}$; Saliva $\left.\times 20 \mathrm{ml}-p=0,071 ; 16,5 \mathrm{ml} \times 20 \mathrm{ml}-p=0,137\right)$, ou seja, houve diferença na ativação muscular de OO e MEL na comparação da performance da saliva em relação ao primeiro volume. Na comparação entre os volumes de água, não foram observadas diferenças significantes. Quando comparados os diferentes volumes na ativação dos músculos testados, não foram encontradas diferenças significantes para GC.

Quanto ao tempo de duração da ativação muscular, foram observadas diferenças significantes para GP em todas as tarefas de deglutição para todos os músculos. De maneira geral, GP apresentou maior duração da atividade muscular durante a deglutição de água se comparada a deglutição de saliva (OO: Saliva $\times 16,5 \mathrm{ml}-p<0,001^{*}$; Saliva $\times 20 \mathrm{ml}-$ $p<0,001^{*} ; 16,5 \mathrm{ml} \times 20 \mathrm{ml}-p=0,612 ;$ MS: Saliva $\times 16,5 \mathrm{ml}-p<0,001^{*}$; Saliva $\mathrm{x}$ $20 \mathrm{ml}-p<0,001^{*} ; 16,5 \mathrm{ml} \times 20 \mathrm{ml}-p=1,000 ; \mathrm{SH}$ - Saliva $\times 16,5 \mathrm{ml}-p=0,025^{*}$; Saliva $\times 20 \mathrm{ml}-p=0,087 ; 16,5 \mathrm{ml} \times 20 \mathrm{ml}-p=1,000$; MEL: Saliva $\times 16,5 \mathrm{ml}-$ $p=0,001^{*}$; Saliva $\left.\times 20 \mathrm{ml}-p=0,39^{*} ; 16,5 \mathrm{ml} \times 20 \mathrm{ml}-p=0,494\right)$. Não foram encontradas nenhuma diferença significante para GC na duração da ativação muscular quando comparados os diferentes volumes. 
Tabela 4 - Comparação intragrupos para amplitude e duração da ativação muscular nos diferentes volumes ofertados

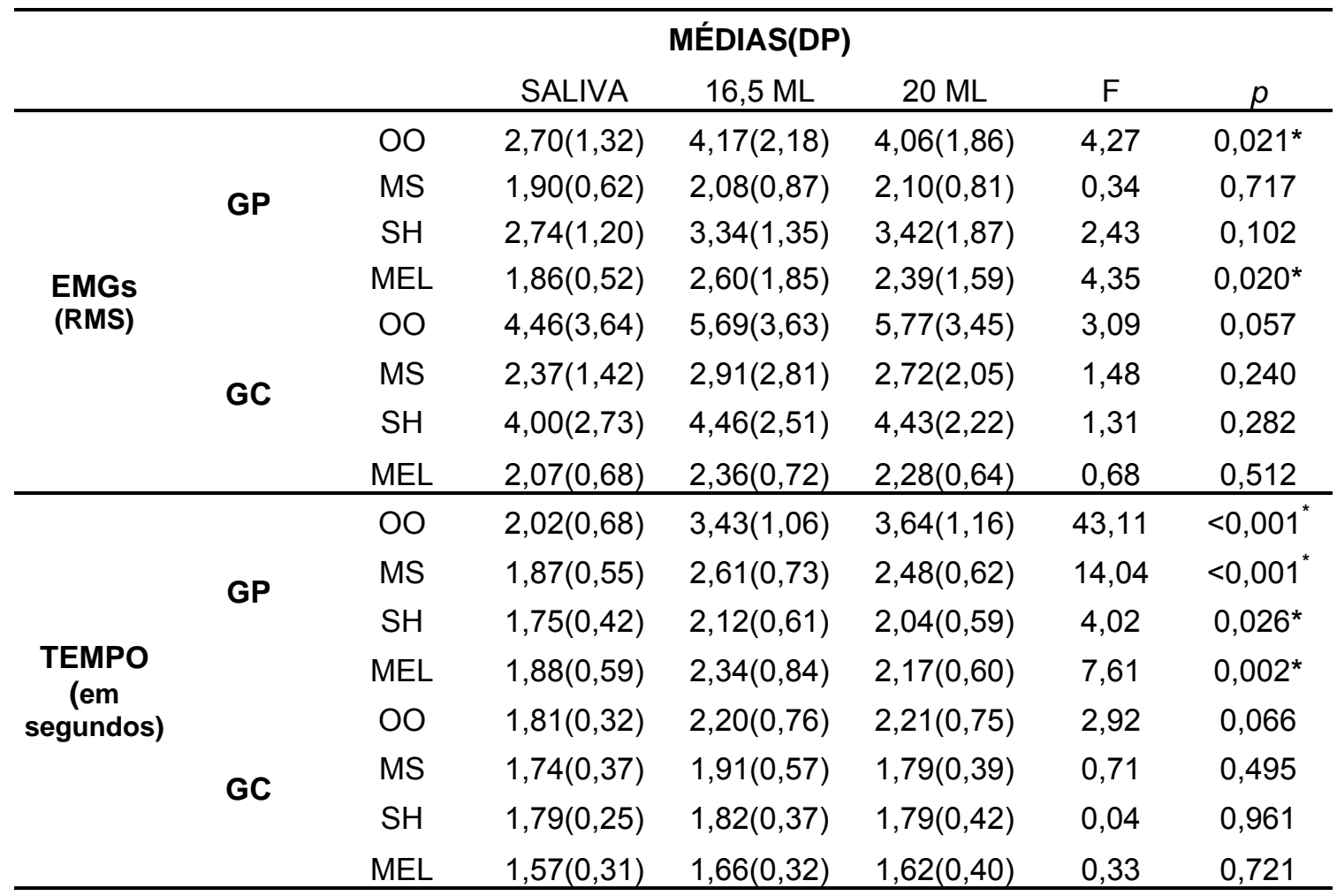

${ }^{*} p$-valores considerados estatisticamente significantes

Legenda: DP: Desvio Padrão;GP: Grupo de Pesquisa ; GC:

Grupo Controle ; RMS: root mean square.

OO:músculos orbicular da boca ; MS: músculo masseter;

$\mathrm{SH}$ :musculatura suprahioidea; MEL:musculatura extrínseca da laringe 


\section{DISCUSSÃO}

Este estudo foi realizado com o objetivo de avaliar as características clinicas da motricidade orofacial e da deglutição de pacientes com DM1 que apresentavam deglutição segura, de acordo com a escala de deglutição ASHA NOMS. A deglutição é um processo complexo, que exige a coordenação precisa de mais de 25 músculos $^{36}$, envolve a contração de vários músculos orofaciais, faringe, laringe, vias respiratórias, esôfago ${ }^{37}$ além de seis pares de nervos cranianos e lóbulo frontal ${ }^{38}$. Nossos resultados sugerem que pacientes com DM1 apresentam déficits significativos relacionados à posição, postura e mobilidade dos órgãos orais miofuncionais e no desempenho relacionado à deglutição e a mastigação. Além disso, os resultados da EMGs para diferentes tarefas de deglutição indicaram maior atividade muscular do orbicular da boca e maior duração da ativação muscular para os músculos: orbicular da boca, masseter e musculatura extrínseca da laringe.

De acordo com o exame clínico (AMIOFE) ${ }^{33}$, os resultados do presente estudo confirmam o que já foi descrito na literatura ${ }^{6,13,21,22,39-41}$, ou seja, a fraqueza muscular como tendo um impacto sobre o sistema miofuncional orofacial e, conseqüentemente, sobre as funções orais como mastigação e deglutição. É importante ressaltar, que no presente estudo a mobilidade dos órgãos motores orais foi a característica clínica que se mostrou mais comprometida. De acordo com a metodologia de aplicação do 
$\mathrm{AMIOFE}^{33}$, a mobilidade é avaliada por meio de movimentos isolados dos lábios, língua, mandíbula e bochechas. Os movimentos são classificados como adequados somente se eles forem precisos e realizados sem qualquer tremor $^{33}$. No presente estudo, vários indivíduos portadores de DM1 apresentaram o fenômeno miotônico durante a realização dos movimentos solicitados. Embora os pacientes fossem capazes de realizar a maioria desses movimentos, esses foram classificados como inadequados devido a dificuldades em executá-los consecutivamente e com a coordenação necessária (ou seja, os movimentos eram lentos e descoordenados).

O protocolo $\mathrm{AMIOFE}^{33}$ não foi especificamente desenvolvido para avaliar pacientes com DM1, mas sim para investigar déficits de motricidade orofacial da população em geral. Por esta razão, não foi realizada uma avaliação específica das características neurológicas, incluindo miotonia. Até recentemente, não existiam escalas funcionais disponíveis para explorar a $\mathrm{DM} 1^{42}$. Vários testes têm sido relatados na literatura, no entanto, estes apresentam aspectos específicos para quantificar de forma global as diferentes doenças e suas características neurológicas especificas ${ }^{43-47}$. Contardi et al. (2012) ${ }^{42}$ apresentaram uma primeira proposta de escala de avaliação clínica e funcional para DM1. A escala proposta pelos autores inclui a avaliação da função neuromuscular e estado de incapacidade de pacientes com DM1. O protocolo envolve a avaliação da força muscular dos dedos, pescoço e músculos distais dos membros superiores e inferiores; densidade dos músculos intercostal e dos principais músculos dos membros 
inferiores; função neuropsicológica e algumas escalas de desabilidades relacionadas a atividades de vida diária e a qualidade do sono. Embora esta seja uma ferramenta muito promissora, ainda não inclui a avaliação do sistema miofuncional oral, e, mais especificamente do impacto da fraqueza muscular e miotonia na deglutição.

Quanto aos resultados da EMGs, pôde ser observado que, durante a deglutição de saliva, o músculo orbicular da boca dos portadores de DM1 apresentou menor ativação que a normalidade. Uma possível explicação para esse resultado é a fraqueza muscular facial generalizada apresentada por esses individuos ${ }^{6,13,22,39-41}$. A literatura ${ }^{13,22,39-41,48}$ aponta que as características marcantes dos portadores de DM1 são: face alongada, respiração oral e lábios entreabertos. Essas características craniofaciais podem contribuir para a diminuição da ativação do músculo orbicular da boca durante a sua funcionalidade e na ativação muscular ${ }^{49}$. Para os demais músculos testados, não se observou diferença na ativação elétrica.

A duração da deglutição na EMGs refere-se ao tempo necessário para completar um ciclo de ativação de um músculo ou de um grupo muscular para a realização do evento. Uma doença que aumenta a duração da atividade do músculo e/ou distúrbios seqüenciais na ativação dos vários músculos envolvidos na deglutição podem aumentar a duração do evento na $E_{M G s}{ }^{50}$. As fases da deglutição podem ser detectadas com sucesso somente se os registros forem feitos com EMGs e com investigação 
radiográfica simultânea ${ }^{35}$. De acordo com a literatura ${ }^{25,26,35,53}$ os eletrodos posicionados em $\mathrm{OO}$ e MS representam a fase oral da deglutição, os eletrodos em MS e SH representam a fase orofaríngea e em MS, SH e MEL correspondem a fase faríngea, $\mathrm{SH}$ e MEL representam a fase inicial esofágica. No presente estudo, para os eletrodos localizados em $\mathrm{OO}, \mathrm{MS}$ e MEL, a duração de EMGs foi significativamente maior em pacientes com DM1 quando comparados ao grupo controle, quando considerando os volumes de água testados. Estes resultados sugerem que pacientes com DM1 necessitam de maior tempo para passar um bolo alimentar da cavidade oral para o esôfago. A maior duração da EMGs no grupo DM1 pode estar relacionado a miotonia e/ou incoordenação dos músculos envolvidos no processo da deglutição ou ainda pode refletir uma possível adaptação fisiológica para a deglutição segura.

A amplitude na EMGs é um aspecto importante na relação entre a força muscular e a atividade elétrica ${ }^{52}$. Considerando todos os diferentes tipos de distúrbios neuromusculares, a amplitude é uma das características mais informativas ${ }^{53}$. Não foi observado aumento significativo na amplitude da EMGs, nos pacientes com DM1, quando comparando os resultados obtidos no teste de água com $16,5 \mathrm{ml}$ e com 20ml (deglutição com estresse). Diferenças significativas foram observadas apenas para os eletrodos localizados em OO e MEL quando comparadas a deglutição de saliva com os diferentes volumes de água. Diferenças significativas foram igualmente observadas para a duração da EMGs, para todos os locais de eletrodos 
testados, quando comparada a deglutição de saliva e os diferentes volumes de água.

A característica marcante da miotonia é a dificuldade de relaxamento do músculo após a contração. Contrações musculares repetidas podem reduzir a miotonia, um recurso conhecido como fenômeno de "aquecimento" ${ }^{54}$. Esse fenômeno poderia explicar o fato de não ter sido encontrada diferença entre os testes de deglutição com 16,5ml e $20 \mathrm{ml}$ de água. Apesar de ter sido respeitado um intervalo entre os testes para evitar a possível fadiga muscular, este intervalo de tempo pode não ter sido suficiente para cancelar as capacidades de acomodação.

O comprometimento da deglutição na DM1 é conhecido desde a descrição da doença por Steinert em $1909^{56}$. A disfagia é um sintoma frequentemente encontrado e tem sido relatada com uma prevalência entre $25 \%$ e $80 \%$ dos indivíduos ${ }^{20,56-59}$. De acordo com os achados do presente estudo, utilizando critérios clínicos e eletrofisiológicos, pacientes com DM1 considerados como tendo uma deglutição segura, apresentam alterações fisiológicas da deglutição. As publicações sobre disfagia nesta população são escassas, principalmente em nosso país. Apesar da disfagia ser um dos sintomas apresentados por pacientes com DM1, pouca ênfase é dada à identificação precoce de alterações da deglutição; a atenção é dada apenas quando a deglutição do paciente já está gravemente comprometida. O tratamento da DM1 envolve modificações de estilo de vida. A identificação 
precoce dos distúrbios da deglutição nessa população permitiria a reabilitação miofuncional oral nos estágios iniciais da patologia (ou seja, o uso de estratégias compensatórias). Acredita-se que a reabilitação precoce poderia diminuir o risco de pneumonia aspirativa.

Estudos futuros se fazem necessários para a investigação do processo de deterioração da deglutição nesta população e de que forma os processos de reabilitação poderiam manter esta função saudável por um maior período de tempo. 


\section{CONCLUSÃO}

Em comparação com indivíduos saudáveis, os pacientes com DM1 apresentaram déficits em posição, postura e mobilidade dos órgãos miofuncionais orais, bem como mastigação e deglutição comprometidas. Em relação aos resultados da EMGs, estes pacientes apresentaram maior duração de tempo para realizar o trajeto do bolo alimentar da cavidade oral para o esôfago. A maior duração da deglutição na EMGs no grupo DM1, possivelmente está relacionada a miotonia e/ou incoordenação dos músculos envolvidos no processo da deglutição ou pode estar relacionado a uma adaptação fisiológica para uma deglutição segura. 


\section{ANEXOS}

\section{ANEXO1}

\section{APROVAÇÃO}

A Comissão de Ética para Análise de Projetos de Pesquisa CAPPesa da Diretoria Clínica do Hospital das Clínicas e da Faculdade de Medicina da Universidade de São Paulo, em sessão de 07/07/2010, APROVOU o Protocolo de Pesquisa $n^{\circ}$ 0350/10, intitulado: "CARACTERIZAÇÃo DAS FUNÇŌES OROFACIAISEM PORTADORES DE DISTROFIA MIOTÔNICA DE STEINERT" apresentado pelo Departamento de FISIOTERAPIA, FONOAUDIOLOGIA E TERAPIA OCUPACIONAL, inclusive o Termo de Consentimento Livre e Esclarecido.

Cabe ao pesquisador elaborar e apresentar à CAPPesq, os relatórios parciais e final sobre a pesquisa (Resolução do Conselho Nacional de Saúde n 196, de 10/10/1996, inciso IX.2, letra "c").

Pesquisador (a) Responsável: Profa. Dra. Claudia Regina Furquim de Andrade Pesquisador (a) Executante: Beatriz Ercolin

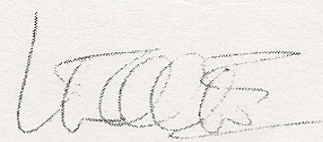

PROF. DR. CLAUDIO LEONE

Vice-Presidente da Comissão Ética para Análise de Projetos de Pesquisa 


\section{ANEXO 2}

\section{HOSPITAL DAS CLÍNICAS DA FACULDADE DE MEDICINA DA UNIVERSIDADE DE SÃO PAULO-HCFMUSP}

MODELO DE TERMO DE CONSENTIMENTO LIVRE E ESCLARECIDO

\section{DADOS DE IDENTIFICAÇÃO DO SUJEITO DA PESQUISA OU RESPONSÁVEL LEGAL}

1. NOME:

DOCUMENTO DE IDENTIDADE N ${ }^{\circ}$ : SEXO :.$M \square F \square$

DATA NASCIMENTO: ......................

ENDEREÇO

$\mathrm{N}^{\circ}$

APTO:

BAIRRO: CIDADE

CEP: TELEFONE: DDD ( ..)

2.RESPONSÁVEL LEGAL

NATUREZA (grau de parentesco, tutor, curador etc.)

DOCUMENTO DE IDENTIDADE : SEXO: $M \square F \square$

DATA NASCIMENTO.: .....................

ENDEREÇO:

$\mathrm{N}^{\circ}$

APTO:

BAIRRO:

CIDADE:

CEP:

TELEFONE:

DDD

DADOS SOBRE A PESQUISA

1. TÍTULO DO PROTOCOLO DE PESQUISA: CARACTERIZAÇÃO DAS FUNÇÕES OROFACIAIS EM PORTADORES DE DISTROFIA MOTÔNICA DE STEINERT PESQUISADOR :Claudia Regina Furquim de Andrade.

CARGO/FUNÇÃO: Professor Titular

INSCRIÇÃO CONSELHO REGIONAL No CRFa/SP 2936.

UNIDADE DO HCFMUSP: Serviço de Fonoaudiologia do Instituto Central .

3. AVALIAÇÃO DO RISCO DA PESQUISA:

$\begin{array}{lll}\text { RISCO MÍNIMO } & X & \text { RISCO MÉDIO } \\ \text { RISCO BAIXO } & \square & \text { RISCO MAIOR }\end{array}$

4.DURAÇÃO DA PESQUISA : 24 meses 


\section{HOSPITAL DAS CLÍNICAS DA FACULDADE DE MEDICINA DA UNIVERSIDADE DE SÃO PAULO-HCFMUSP}

Esta pesquisa tem como objetivo verificar se existe alguma dificuldade/alteração na sua forma de mastigar, engolir, respirar e o funcionamento de todos os músculos do seu rosto e da sua boca. Esta avaliação é importante para que as dificuldades em engolir sejam melhor compreendidas e com isso possa ser oferecido o tratamento mais adequado. Esta pesquisa é importante porque não existem muitos estudos nessa área, principalmente aqui no Brasil.

Cada pessoa que participar da pesquisa fará uma avaliação de todos os músculos do rosto e da boca. Esta avaliação será realizada em dois dias. Você deverá realizar alguns movimentos com a sua boca e língua conforme as instruções dadas pela pesquisadora. No primeiro dia, para verificar como você mastiga e engole, será pedido que você coma meio pão francês. No segundo dia, para avaliar como você engole, será utilizado um equipamento especial. Para isso serão colados no seu rosto oito bolinhas de metal (eletrodos) com o objetivo de verificar como seus músculos estão funcionando enquanto você bebe água. Esse exame não dói e não provoca qualquer tipo de desconforto.

Além de ajudar no trabalho com pessoas com dificuldade para mastigar, engolir ou, respirar, a pessoa que participar da pesquisa e apresentar qualquer alteração dos músculos do rosto ou na forma de mastigar e engolir receberá atendimento fonoaudiológico específico, oferecido pelo Serviço de Fonoaudiologia do Instituto Central do Hospital das Clínicas da Faculdade de Medicina da Universidade de São Paulo. 
O participante da pesquisa poderá, a qualquer momento, ter acesso aos procedimentos, riscos e benefícios relacionados à pesquisa. Poderá, também, solicitar qualquer esclarecimento à pesquisadora sobre dúvidas que venham a surgir durante a realização da pesquisa.

Poderá retirar o consentimento de participação na pesquisa a qualquer momento e assim, deixar de participar do estudo. Esta atitude não trará nenhum tipo de prejuízo à continuidade de assistência que o participante possa vir a necessitar. O principal investigador é a Dra. Fernanda Chiarion Sassi que pode ser encontrada no endereço Rua Cipotânea, 51- Cidade Universitária São Paulo/SP, CEP. 05360-160 Telefone(s) 3091-7453. Se você tiver alguma consideração ou dúvida sobre a ética da pesquisa, entre em contato com o Comitê de Ética em Pesquisa (CEP) - Rua Ovídio Pires de Campos, 225 - $5^{\circ}$ andar - tel: 3069-6442 ramais 16, 17, 18 ou 20, FAX: 3069-6442 ramal 26 - Email: cappesq@hcnet.usp.br

Todos os dados obtidos, bem como a identidade de cada participante da pesquisa, serão mantidos em sigilo e somente a pesquisadora responsável pelo estudo terá acesso aos dados para análise e discussão.

Acredito ter sido suficientemente clara a respeito das informações que li ou que foram lidas para mim, descrevendo o estudo "CARACTERIZAÇÃO DA DEGLUTIÇAO EM PORTADORES DE DISTROFIA MOTÔNICA DE STEINERT". Eu discuti com a Profa. Dra. Claudia Regina Furquim de Andrade e/ou a Fonoaudióloga Beatriz Ercolin sobre a minha decisão em participar nesse estudo. Ficaram claros para mim quais são os propósitos do estudo, os procedimentos a serem realizados, seus desconfortos e riscos, as garantias de confidencialidade e de esclarecimentos permanentes. Ficou claro também que minha participação é isenta de despesas e que tenho garantia do acesso a tratamento hospitalar quando necessário. Concordo voluntariamente em 
participar deste estudo e poderei retirar o meu consentimento a qualquer momento, antes ou durante o mesmo, sem penalidades ou prejuízo ou perda de qualquer benefício que eu possa ter adquirido, ou no meu atendimento neste Serviço.

Assinatura do paciente/representante legal

Data 11

Assinatura da testemunha

Data 11

para casos de pacientes menores de 18 anos, analfabetos, semi-analfabetos ou portadores de deficiência auditiva ou visual.

(Somente para o responsável do projeto)

Declaro que obtive de forma apropriada e voluntária o Consentimento Livre e Esclarecido deste paciente ou representante legal para a participação neste estudo. 


\section{REFERÊNCIAS}

1. Harley HC, Brook JD, Rundle SA, et al (1992) Expansion of an unstable DNA region and phenotypic variation in myotonic dystrophy. Nature 355(6360):545-6.

2. Shaw DJ, Harper PS (1989) Myotonic dystrophy: developments in molecular genetics. BR Med Bull 45(3):745-59.

3. Harley HG, Rundle SA, MacMillan JC, et al (1993) Size of the unstable CTG repeat sequence in relation to phenotype and parental transmission in myotonic dystrophy. Am J Hum Genet 52(6):1164-74.

4. Mathieu J, Allard P, Potvin L, et al (1999) A 10 year study of mortality in a cohort of patients with myotonic dystrophy. Neurology 52(8):1658-62.

5. Yotova V, Labuda D, Zietkiewicz E, et al (2005) Anatomy of a founder effect: myotonic dystrophy in Northeasten Quebec. Hum Genet 117(2-3):17787.

6. Gagnon C, Chouinard MC, Laberge L, et al (2010) Health supervision and anticipatory guidance in adult myotonic dystrophy type 1 . Neuromuscul Disord 20(12):847-51. doi:10.1016/j.nmd.2010.08.006.

7. Peñarrocha M, Bagan JV, Vilchez et al (1990) Oral alterations in Steinert'smyotonic dystrophy: a presentation of two cases. Oral Surg Oral Med Oral Pathol 69(6):698-700.

8. MercierJ, Bennani F, Ferri J, et al (1995) Maxillofacial manifestations of Steinert's myotonic dystrophy. Rev Stomatol Chir Maxillofac 96(2):74-82. 
9. Sovari AA, Bodine CK, Farokin F (2007) Cardiovascular manifestation of myotonic dystrophy-1. Cardiol Rev 15(4):191-4. doi: 10.1097/CRD.0b013e318070d1a7.

10. Ramig LA, Scherer RC, Titze IR, et al (1988) Acoustic analysis of voice of patients with neurologic disease: rationale and preliminary data. Ann Otol Rhinol Laryngol 97(2 Pt 1):164-72.

11. Salomonson J, Kawamoto H, Wilson J (1988) Velopharyngeal incompetence as the presenting symptom of myotonic dystrophy. Cleft Palate J 25(3):296-300.

12. Weinberg B, Bosma JF, Shanks JC, et al (1968) Myotonic dystrophy initially manifested by speech disability. J Speech Hear Disord 33(1):51-9.

13. deSwart BJ, van Engelen BG, van de Kerkhof JP, et al (2004) Myotonia and flaccid dysarthria in patients with adult onset myotonic dystrophy. J Neurol Neurosurg Psychiatry 75(10):1480-02. doi:10.1136/jnnp.2003.032151. 14. Darley FL, Aronson AE, Brown JR (1975) Motor speech disorders. WB Saunders Co, Philadelphia.

15. McNeil MR (1997) Clinical management of sensorimotor speech disorders. Thieme, Stuttgart.

16. de Die Smulders CE, Höweler CJ, Thijs C et al (1998) Age and causes of death in adult-onset myotonic dystrophy. Brain 121:1557-63.

17. Garret JM, DuBose TD Jr, Jackson JE, et al (1969) Esophageal and pulmonary disturbance in myotonia dystrophica. Arch Intern Med 123(1):2632. 
18. Hughes DT, Swann JC, Gleeson JA, et al (1965) Abnormalities in swallowing associated with dystrophica myotonica. Brain 88(5):1037-42.

19. Gillarn PM, Heaf PJ, Kaufman L, et al (1964) Respiration in dystrophia myotonica. Thorax 19:112-20.

20. Harvey JC, Sherbourne DH, Siegel Cl (1965) Smoorth muscle involvement in myotonic dystrophy. Am J Med 39:81-90.

21. Ertekin C, Yüceyar N, Aydogdu I, et al (2001) Electrophysiological evaluation of oropharyngeal swallowing in myotonic dystrophy. J Neurol Neurosurg Psychiatry 70(3):363-371. doi: 10.1136/jnnp.70.3.363.

22. Chiappetta AL, Oda AL, Zanoteli E, et al (2001) Oropharyngeal dysphagia in the myotonic dystrophy: phonoaudiological evaluation and nasofibrolaryngoscopical analysis. Arq Neuropsiquiatr 59(2-B):394-400.

23. Turner C, Hilton-Jones D (2010) The myotonic dystrophies: diagnosis and management. J Neurol Neurosurg Psychiatry 81(4):358-67. doi: 10.1136/jnnp.2008.158261.

24. Eisenhuber E, Schima W, Schober E, et al (2002) Videofluoroscopic assessment of patients with dysphagia: pharyngeal retention is a predictive fator for aspiration. AJR Am J Roentgenol 178(2):393-8.

25. Ertekin C, Aydogdu I, Yüceyar N (1996) Piecemeal deglutition and dysphagia limit in normal subjects and in patients with swallowing disorders. J Neurol Neurosurg Psychiatry 61(5):491-6.

26. Vaiman M (2007) Standardization of surface electromyography utilized to evaluate patients with dysphagia. Head Face Med 3:26. doi:10.1186/1746$160 X-3-26$ 
27. Ertekin C, Aydogdu I, Yüceyar N, et al (1988) Electrodiagnostic methods for neurogenic dysphagia. Electroencephalogr Clin Neurophysiol 109(4):33140.

28. Alfonsi E, Veríssimo M, Merlo IM, et al (2007) Electrophysiologic patterns of oral-pharyngeal swallowing in parkinsonian syndromes. Neurology 68(8):583-90.

29. Coriolano MD, Belo LR, Carneiro D, et al (2012) Swallowing in patients with Parkinson's disease: a surface electromyography study. Dysphagia [epub ahead of print]. doi 10.1007/s00455.012-9406-0.

30. Rockville, MD (1998) American Speech-Language-Hearing Association National Outcome Measurement System (NOMS). Adult Speech-Language Pathology training manual, ASHA.

31. Wesling M, Brady S, Jensen M, et al (2003) Dysphagia outcomes in patients with brain tumors undergoing inpatient rehabilitation. Dysphagia18:203-210. doi: 10.1007/s00455-002-0098-8.

32. Merletti R. Standards for Reporting EMG data. Journal of Electromyography and Kinesiology. 1999;9(1):III-IV

33. Felício CM, Ferreira CL (2008) Protocol of orofacial myofunctional evaluation with scores. Int $\mathrm{J}$ Pediatr Otorhinolaryngol 72(3):367-75. doi:10.1016/j.ijporl.2007.11.012.

34. Soderberg GL, Cook MT. Electromyography in biomechanics. Phys Ther. 64(12):1813-20, 1984. 
35. Vaiman M, Eviatar E, Segal S (2004) Evaluation of normal deglutition with the Help of Rectified surface electromyography records. Dysphagia 19:125-132. doi:10.1007/s00455-003-0504-x.

36. Bordon A, Bokhari R, Sperry J, et al (2011) Swallowing dysfunction after prolonged intubation: analysis of risk factors in trauma patients. Am J Surg 202:679-682. doi: 10.1016/j.amjsurg.2011.06.030.

37. Klahn MS, Perlman Al (1999) Temporal and durational patterns associating respiration and swallowing. Dysphagia 14:131-138. doi: 10.1007/PL00009594.

38. Brown CV, Hejl K, Mandaville AD, et al (2011) Swallowing dysfunction after mechanical ventilation in trauma patients. J Crit Care 26:108.e9108.e13. doi: 10.1016/j.jere.2010.05.036.

39. Conravey A, Santana-Gould L (2010) Myotonia congenita and myotonic distrophy: surveillance and management. Curr Treat Options Neurol 12(1):16-28. doi: 10.1007/s11940-009-0055-z.

40. Araújo FS, Bessa Júnior RC, Castro $\mathrm{CH}$, et al (2006) Anesthesia in a patient with Steinert disease: case report. Rev Bras Anestesiol 56(6):649-53. 41. Buchholz DW (1994) Dysphagia associated with neurological disorders. Acta Otorhinolaryngol Belg 48(2):143-55.

42. Contardi S, Pizza F, Falzoni F, et al (2012) Development of a disability scale for myotonic dystrophy type 1. Acta Neurol Scand 125:431-438. doi:10.1111/j.1600-0404.2011.01587.x.

43. Hammarén E, Kjellby-Wendt G, Linderberg C (2005) Quantification of mobility impairment and self-assessment of stiffness in patients with 
myotonia congenita by the physiotherapist. Neuromuscul Disord 15(910):610-7. doi:10.1016/j.nmd.2005.07.002.

44. Kierkegaard M, Tollbäck A (2007) Reliability and feasibility of the six minute walk test in subjects with myotonic dystrophy. Neuromuscul Disord 17(11-12):943-9. doi:10.1016/j.nmd.2007.08.003.

45. Moxley RT3rd, Logigian EL, Martens WB, et al (2007) Computerized hand grip myometry reliably measures myotonia and muscle strength in myotonic dystrophy (DM1). Muscle Nerve 36(3):320-8. doi: 10.1002/mus.20822.

46. Sansone V, Marinou K, Salvucci J, et al (2000) Quantitative myotonia assessment: an experimental protocol. Neurol Sci 21(5 Suppl):S971-4.

47. Vincent KA, Carr AJ, Walburn J, et al (2007) Construction and validation of a quality of life questionnaire for neuromuscular disease (INQoL). Neurology 68(13):1051-7.

48. Fu YH, Pizzuti A, Fenwick RG Jr et al (1992) An unstable triplet repeat in a gene related to myotonic muscular dystrophy. Science 255(5049):1256-8. 49. Ambrosio AR, Trevilato PC, Martins, et al (2009) Electromyography eveluation of the upper lip according to the breathing mode: a longitudinal study. Braz Oral Res 23(4):415:23.

50. Vaiman M, Gabriel C, Eviatar E, et al (2005) Surface electromyography of continuous drinking in healthy adults. Laryngoscope 115(1):68-73. doi: 10.1097/01.mlg.0000150673.53107.20 
51. Ertekin C, Tarlaci S, Aydoglu I, et al (2002) Electrophysiological evaluation of pharyngeal phase of swallowing in patients with Parkinson's disease. Mov Disord. 17(5):942-9. doi: 10.1002/mds. 10240

52. Isley MR, Kranss GL, Levin $\mathrm{KH}$, et al Electromyography/Eletroencephalography. SpaceLab Medical, Redford, WA. 53. Wilbourn AJ, Ferrante MA (2000) Clinical electromyography. In: Joynt RJ, Griggs RC (eds) Baker's clinical neurology (book on CD-ROM). WB Saunders, Philadelphia.

54. Cooper RG, Stokes MJ, Edwards RH (1988) Physiological characterization of the "warm-up" effect of activity in patients with myotonic dystrophy. J Neurol Neurosurg Psychiatry 51(9):1134-41.

55. Harper PS (1989) Myotonic dystrophy, $2^{\text {nd }}$ ed. WB Saunders, London, UK.

56. Schuman BM, Rinaldo JAJr, Darnley JD (1965) Visceral changes in myotonic dystrophy. Ann Intern Med 63(5):793-9.

57. Pruzanski W, Profis A (1966) Dysfunction of alimentary tract in myotonic dystrophy. J Med Sci 2(1):59-64.

58. Willig TN, Paulus J, Lacau Saint Guily J, et al (1994) Swallowing problems in neuromuscular disorders. Arch Phys Med Rehabil 75(11):1175:81.

59. Rönnblom A, Forsberg H, Danielsson A (1996) Gastrointestinal symptoms in myotonic muscular dystrophy. Scan J Gastroenterol 31(7):6547. 